Mirai. Estudios Japoneses

ISSN-e: 1988-2378

http://dx.doi.org/10.5209/MIRA.57104

\title{
Del viaje del turista al viaje del héroe. Mímesis cinematográfica del discurso turístico japonés sobre españa. El caso de Andarushia (2011)
}

\author{
Marcos P. Centeno Martín ${ }^{1}$
}

Resumen: Este trabajo se centra en el imaginario que de España se transmite a través del film Andalucía: La Venganza de la Diosa (Andarushia: Megami no Hōfuku, 2011) de Nishitani Hiroshi. Se propone abordar las relaciones entre cine y turismo con una metodología inversa a la habitual. Frente a la literatura que ha tratado el impacto del cine en el turismo, este estudio plantea por el contrario, el impacto del turismo en el cine. Por un lado, se investiga la adaptación del viaje turístico por España promovido por las agencias japonesas en la narración cinematográfica. Este acercamiento pone de relieve un fenómeno de reapropiación de una iconografía tipo preexistente fuera de la gran pantalla. Andalucía recurre a visiones esencialistas de España dirigidas a seducir a la audiencia con imágenes que paradójicamente, el público japonés ya conoce. Por otro lado, se evalúa la renovación del imaginario de España. Primero, mediante figuras transnacionales que generan un exotismo novedoso, encarnan las fantasías de espectador / turista japonés y proyectan relaciones simbólicas de poder de Japón con España y Estados Unidos. Segundo, la representación del destino turístico reconvertido en localización cinematográfica se actualiza con referentes a la corrupción financiera que aluden a aspectos de la actualidad española.

Palabras claves: Cine; turismo; Nishitani; iconografía; española.

\section{[en] From a Tourist Journey to a Hero Journey. Film Mimesis in the Japanese Tourist Discourse on Spain: The Case of Andalucia (2011)}

\begin{abstract}
This text interrogates the imaginary of Spain in the film Andalucia: Revenge of the Goddess (Andarushia Megami no Hōfuku, Hiroshi Nishitani, 2011). The relations between film and tourism are tackled with a methodology inverse to that usually used. In contrast to the literature dealing with the impact of film on tourism, this work assesses the impact of tourism on film. On one hand, it studies the adaptation of a journey across Spain promoted by Japanese travel agencies into de cinematic narrative. This approach brings to the forefront an appropriation of iconography pre-existing beyond the big screen. Andalucia draws on essentialist views of Spain with an aim to seduce audiences with images that paradoxically, the Japanese audience already knows. On the other hand, this article explores the renewal of the Spanish imaginary, first, through transnational figures creating a novel exoticism, embodying the fantasies of the Japanese spectatortourist and projecting symbolic power relations of Japan with Spain and the U.S. Second, the representation of the tourist destination transformed into a film location is updated with references to financial corruption that seem to evoke issues of Spanish current affairs.
\end{abstract}

Keywords: Cinema; tourism; Nishitani; Spanish; iconography.

Sumario. Introducción. Imagen y turismo. La iconografía extranjera de España. Andalucía y la construcción japonesa de España. "El viaje" en el discurso turístico-cinematográfico. Transferencia iconográfica: del folleto turístico al cine. Turismo de películas y películas de turismo. Relaciones sexualizadas de Japón con Occidente. Corrupción: ¿nuevos estereotipos?. Conclusión.

Cómo citar: Centeno Martín, M. P. (2017). Del viaje del turista al viaje del héroe. Mímesis cinematográfica del discurso turístico japonés sobre españa. El caso de Andarushia (2011), en Mirai. Estudios Japoneses 1(2017), 93-111.

Japan and Korea Department. SOAS, University of London.

mc100@soas.ac.uk 


\section{Introducción}

La relación entre cine y turismo ha experimentado un renovado interés en los últimos años. Los miembros del grupo de investigación CITUR (Cine, Imaginario y Turismo) creado en la Universitat de València han abordado el diálogo entre cine y turismo desde múltiples perspectivas: desde el estudio de las producciones españolas utilizadas para fomentar el turismo extranjero a partir de cierta imaginería preexistente ${ }^{2}$, hasta el análisis de films encaminados a sustituir estereotipos por una visión más actualizada del país ${ }^{3}$. Frente a los estudios semiológicos, de la imagen, iconografías y discursos cinematográficos, otros autores se han acercado al caso japonés desde los estudios culturales para centrarse en el impacto del cine en el turismo de aquel país ${ }^{4}$. Sin embargo, el estudio de caso aquí abordado, Andalucía: La Venganza de la Diosa (Andarushia: Megami no Höfuku) (2011) de Nishitani Hiroshi, plantea varios matices diferentes. En primer lugar, Andalucía no es una película española destinada a fomentar el turismo nacional, ni tampoco es un film con un potencial impacto sobre el turismo en Japón. Se trata de analizar el caso de una producción japonesa que utiliza el imaginario español para sus propios fines narrativos. En segundo lugar, la metodología empleada es inversa a la de los estudios anteriores: este texto no busca analizar la influencia del cine en el turismo, sino al contrario, el impacto del turismo en el cine. El interés de este trabajo es concretamente evaluar el impacto del discurso turístico en la narración cinematográfica. Con este fin el enfoque epistemológico no es la teoría turística, ni la historia del cine sino el análisis textual comparado entre los folletos turísticos japoneses y el film Andalucía, prestando atención a la transferencia de modelos visuales, retóricos y esquemas narrativos. Tercero, aunque la construcción de un imaginario de España desde el Lejano Oriente es un fenómeno cada vez menos inusual, se trata de un caso todavía poco estudiado que sin embargo puede aportar interesantes contribuciones a la discusión sobre la compleja configuración iconográfica de España a través del cine, hasta ahora dominado por relatos occidentales.

\section{Imagen y turismo}

Aunque la historiografía del turismo en España cuenta con una literatura ya asentada, la historia crítica del discurso turístico en este país tan sólo se ha empezado a escribir en los últimos años. Las propuestas desde la perspectiva de los estudios de la comunicación ${ }^{5}$ o de la imagen ${ }^{6}$ han aportado interesantes claves, porque como señala Afinoguénova, requieren de una duda metódica sobre los discursos y sus usos sociales asociados a la

2 Del Rey Reguillo, Antonia (ed.) (2007): Cine, imaginario y turismo: Estrategias de seducción. Valencia: Tirant lo Blanch, pp. 9-31

3 Mestre, Rosanna / Del Rey Reguillo, Antonia / Stanishevski, Konstantin (2008): “The Image of Spain as Tourist Destination Built Through Fictional Cinema". En: Journal of Travel \& Tourism Marketing, vol. 24, n 2-3, pp. 185-194.

4 SEAton, Philip (2014): "Taiga dramas and tourism: historical contents as sustainable tourist resources". En: $J a$ pan Forum, 27: 1, pp. 82-103; Nishikawa, Katsuyuki, Seaton, Philip / Yamamura, Takayoshi (eds.) (2015): The Theory and Practice of Contents Touris, Sapporo: Research Faculty of Media and Communication, Hokkaido University.

5 Stanishevski, Konstantin (2007): “La comunicación de los destinos turísticos”. En: Del Rey Reguillo, Antonia (Ed.), Cine, imaginario y turismo..., op. cit., pp.245-267.

6 Mestre, Rosanna (2007): “Anime español para otaku japoneses”. En: Ibid., pp. 211-241. 
promoción del turismo ${ }^{7}$. Estudiar estas prácticas narrativas es especialmente significativo en el cine porque éste ocupa un lugar destacado en las relaciones del turismo con los medios de comunicación. Como ha señalado Del Rey, el cine es un innegable fabricante de mitologías modernas, por tanto es un agente de primer orden para inducir "la mirada turística y condicionar la elección de los destinos"8. De las contribuciones aportadas por los mencionados autores se extrae una paradójica conclusión; al contrario de lo que cabría esperar, es cine de ficción y no tanto el documental, el que posee mayor capacidad de persuasión sobre el espectador y potencial turista. Como consecuencia, este formato viene a ser uno de los más decisivos agentes en la creación de la imagen de un destino, o siendo más precisos, en la creación de la imagen como destino. En este sentido, las películas de ficción tiene un papel primordial por dos razones: primero, por las condiciones de recepción y los conocidos mecanismos de identificación articulados sobre el espectador, produciendo un "efecto realidad" sobre el relato9. Segundo, porque en el cine de ficción, los mensajes no se perciben como publicitarios; la audiencia tiende a aceptar la historia de ficción como real y suspender su incredulidad ${ }^{10}$. Como indica Mestre, cuanto más se aleja una película del discurso publicitario, más fácilmente suscita en el espectador una predisposición favorable hacia los contenidos, lo cual a la postre resulta una estrategia de promoción más eficaz y persuasiva ${ }^{11}$.

Históricamente, la construcción de la imagen como destino se desarrolló ligada a la modernidad y a una nueva forma de percibir la realidad, basada en la mirada y lo efímero. Desde la invención de los primeros aparatos fotomecánicos de captura y representación de la realidad, los sujetos en la modernidad ya no estaban movidos por descubrir territorios ignotos o la experiencia de vivir en ellos. A diferencia de los antiguos exploradores, se convirtieron en turistas cuyo interés por lo exótico comenzó a estar ligado a la voluntad de registrar visualmente su recorrido y verificar a través de sus fotografías otras imágenes ya conocidas y preparadas ${ }^{12}$. De esta manera, los primeros turistas modernos, a finales del siglo diecinueve, ya creaban sus propias imágenes geografías remotas ajustadas a iconografías previamente conocidas. El cine se contagió de estas prácticas desde los inicios. La antropología visual desde los años ochenta han aportado interesantes herramientas epistemológicas para analizar cómo las imágenes en movimiento crearon un imaginario del "otro", que en realidad respondía a las expectativas, prejuicios y otras ensoñaciones preexistentes ${ }^{13}$.

El encuentro con lo remoto en la actividad cinematográfica y turística tiene importantes paralelismos. MacCannel definió el turismo como un viaje en contra de las divi-

\footnotetext{
Afinoguénova, Eugenia (2007): "Discurso del Turismo en la configuración de la identidad nacional para España". En: Ibid., pp. 35-53.

8 Del Rey Reguillo, Antonia (2007): "Introducción”. En: Ibid., p. 12.

9 Quintana, Ángel (2004): "Imatge, cinema i turisme. Algunes construccions imaginaries per al desig". En: AA.Vv, Tour-ismes. La derrota de la dissensió, Barcelona: Fundació Antoni Tapies / Forum Barcelona, pp. 124.

10 Quintana, Ángel (2003): Fabulas de lo visible. El cine como creador de realidades, Barcelona: Acantilado.

11 Mestre, Rosanna (2007): “Anime español ...op. cit., p. 224.

12 Del Rey Reguillo, Antonia (2007): "Introducción”...op. cit., p.16.

13 De France, Claudine (1995): "Cuerpo, materia y rito en el cine etnográfico". En: Ardévol, Elisenda y Peréz Tolón, Luis (eds.), Imagen y Cultura: perspectivas del cine etnográfico. Granada: Biblioteca de Etnología, Diputación de Granada, pp.234-235; MacDougall, David (1992): "Whose story is it". En: Claford, Peter / Simonsen, Jan, Ethnographic Film Aesthetic and Narrative Tradition. Aarhus: Intervention Press. En otra ocasión hemos tratado la construcción de la otredad en las primeras representaciones cinematográficas del Extremo Oriente, centrada en el pueblo ainu de Japón, vid. Centeno Martín, Marcos (2014): "Las grietas de la imagen. Una mirada a la trastienda de los primeros documentales etnográfico sobre el pueblo ainu (1897-1936)". En: Secuencias, $\mathrm{n}^{\circ} 40$, pp.62-80.
} 
siones del tiempo y espacio abiertas por la modernidad, basado en una búsqueda por lo "autentico"14. Para ello, se propone el contacto con un patrimonio cultural que se percibe como desplazado en el tiempo — anclado en el pasado- y en el espacio — ubicado en lugares distintos al origen del turista - . De forma similar, la experiencia cinematográfica recurre a menudo a un imaginario de origen distante en términos históricos y geográficos, pero a su vez, de alguna manera conocida por el espectador. Aunque el relato fílmico se moldee por influencias de procedencia diversa y con el objetivo de asombrar al público, las imágenes no dejan de convertirse en una engañosa garantía de realidad ${ }^{15}$.

\section{La iconografía extranjera de España}

Mucho antes de la invención del cinematógrafo, el imaginario extranjero sobre España se fue construyendo por medio de la literatura. Desde los primeros viajeros del siglo diecisiete hasta los autores del diecinueve como Washington Irving y Prosper Mérimée se conformó un corpus mitológico que aún sin ajustarte demasiado a la realidad, se convirtió en un referente de lo hispano ${ }^{16}$. España es un caso paradigmático en el estudio de iconografías nacionales porque parte de un imaginario fuerte, basado en prejuicios muy asentados procedentes de escritores esencialmente románticos que lo caracterizaron como un lugar exótico, primitivo y en consecuencia, algo incomodo e inseguro. Estos prejuicios fácilmente se trasladaron a la gran pantalla y como ha observado Del Rey, el cine tanto extranjero como nacional, no hizo más que favorecer dichos estereotipos, girando en torno a lo taurino, el pintoresquismo paisajístico, el bandolerismo y el mito de Carmen ${ }^{17}$.

No obstante, dicha iconografía española se fue desarrollando eminentemente en Occidente. Como ha observado Bustelo, España no goza en Japón de una identidad sólida equiparable a Europa o América Latina, aunque predominan algunos estereotipos tradicionales: futbol, flamenco, toros, alejados de la realidad ${ }^{18}$. Pese a ello, según Mestre, España recientemente parece despertar en Japón una gran simpatía, siendo percibido "como un país moderno y no moderno a la vez, occidental pero muy distinto a los occidentales"19. Mestre se basa en un estudio PME (Proyecto Marca España en (SEEI, 2005) donde se sugiere que aunque en la población japonesa no predomina una imagen negativa del país, los rasgos que la constituyen son en algunos aspectos más propios del España pre-democrática, o incluso pre-moderna, que de la actual.

\section{Andalucía y la construcción japonesa de España}

El film Andalucía presenta ciertas claves a través de las cuales observar la construcción japonesa actual del imaginario español y del rol que el relato turístico tiene en este proceso. En Japón, existen intentos de promoción turística por medio de produc-

\footnotetext{
14 MacCannell, Dean (1976): The Tourist: A New Theory of The Leisure Class. New York: Schocken Books, pp. 11-13.

15 Augé, Marc (1998), El viaje imposible. Barcelona: Gedisa, p.66.

16 Mestre, Rosanna, Del Rey, Antonia y Stanishevski, Konstantin (2008): “The Image of Spain..., op. cit., p. 187.

17 Del Rey Reguillo, Antonia (2007): "Introducción”, op. cit.

18 Bustelo, Pablo (2006): La Política Exterior de España con Asia-Pacífico: Prioridades y Retos. Madrid: Instituto Elcano, p.59.

19 Mestre, Rosanna (2007): “Anime español ..., op. cit.,p. 220.
} 
ciones audiovisuales, como la serie televisiva Yae no Sakura (2013) sobre la vida de Niijima Yae (1845-1932), combatiente contra las tropas imperiales durante el sitio del castillo Tsuruga Castle durante la guerra Boshin y enfermera durante las guerras con China y Rusia, natural de Aizu-Wakamatsu, Fukushima. Esta serie fue emitida por el canal público NHK con el objetivo de atraer turismo a dicha prefectura después del desastre de la planta nuclear y el tsunami del 11 de marzo de 2011. Otro significativo ejemplo es el caso del film de animación Gisaku (Baltasar Pedrosa, 2005), que nace de una iniciativa institucional para promocionar España en Japón a partir de la Exposición Internacional de Aichi de 2005. El objetivo de Gisaku era tratar de revertir aquellos estereotipos negativos que proyectan la idea de España como un país anclado en el pasado y sustituirlos por imágenes de progreso, desarrollo tecnológico, innovación y nuevas infraestructuras ${ }^{20}$. Sin embargo, Andalucía es un caso significativamente diferente a los anteriores. No se trata de un proyecto institucional ni tampoco surge con el objetivo de promover el turismo de España o Japón, es la segunda parte de una serie de películas policíacas para el canal Fuji TV, que recurre a una batería de referentes iconográficos reconocibles, disponibles en otros medios y previamente explotados por la industria turística, con la intención de construir un relato cinematográfico de ficción atractivo para el público japonés. Dicho de otro modo, el objetivo no es hacer que el film tenga un impacto positivo en el turismo sino hacer que los referentes turísticos repercutan en el éxito del film.

De este modo, Andalucia es habitualmente asociada al kankō eiga, o cine turístico, no porque sea un film dedicado a la promoción de un país, sino porque reproduce aspectos narrativos, icónicos y simbólicos del discurso turístico. El film pertenece a la serie protagonizada por el agente diplomático Kuroda Kusaku (Oda Yuji) que trabaja para la oficina japonesa de lucha contra el terrorismo. Este personaje apareció por primera vez en Amalfi: Recompensa de la diosa (Amarufi: Megami no hōshū, 2009) dirigido por Nishitani Hiroshi. Tras su éxito, se estrenó una serie de dos películas televisivas sobre este personaje: la primera fue Diplomático Kusaku Kuroda (Gaikoukan Kuroda Kosaku) emitido en Fuji TV, en enero de 2011, dirigido por Nishisaka Mizuki y Nagayama Kozo. El segundo film fue Andalucía, dirigida de nuevo por Nishitani, coproducida por Tōhō y FujiTV y estrenado en cines en junio de 2011.

Originalmente, Diplomático Kusaku Kuroda estaba basado en una novela de Shinpo Yūichi, cuyo relato se sitúa entre San Francisco, Tokio y México. En cambio, una parte importante de la versión cinematográfica se traslada a Roma y a la población italiana de Amalfi. La historia se inicia con el secuestro de una joven japonesa en Roma. A la embajada de Japón en Italia acaba de llegar el diplomático Kuroda, quien después de rescatar a otro japonés en Bolivia, había sido enviado a San Francisco para hacer de guardaespaldas del Ministro de Exteriores nipón durante la cumbre de la Organización Mundial del Comercio. En Italia, se encuentra con Shimomura Takeshi (Kagawa Teruyuki) con quien había trabajado en México once años antes y sobre el cual recaen las sospechas de varios crímenes.

Guiños al primer estreno cinematográfico y al film televisivo se pueden encontrar en Andalucía, aunque la trama es independiente y puede seguirse sin conocer los argumentos precedentes. En esta ocasión, Kuroda recibe el encargo de investigar la

20 Estudiado por Mestre, Rosanna (2007). No obstante, Del Rey (2007), op.cit. señala que durante la época del general Primo de Rivera ya existió un intento de contrarrestar la imagen incivilizada del país difundida por promotores extranjeros por medio del cine, intentando conciliar tradición y modernidad. 
muerte de un inversor japonés es asesinado en Andorra, que parece relacionado con asunto de un blanqueo de dinero. La principal sospechosa es Shindo Yuka (Kuroki Meisa) una joven agente del Banco Victor, quien a su vez está siendo perseguida y corre el peligro de ser asesinada. Otro investigador de la Interpol, Kotari Makoto (Itō Hideaki) está investigando el asesinato e intenta dejar a Kuroda fuera del caso. Para proteger a Yuka, Kuroda se la lleva acompañado por Makoto al consulado japonés de Barcelona, donde son atacados. Entonces los tres personajes emprenden la travesía hacia Andalucía, donde alguien del Banco Victor ha transferido una gran cantidad de dinero procedente de préstamos corruptos.

\section{"El viaje" en el discurso turístico-cinematográfico}

En realidad, toda la narración se estructura en forma de viaje, que lleva a los protagonistas de París a Barcelona y de allí a Ronda, provincia de Málaga. Esto no es un hecho singular pues el cine ha estado vinculado a la idea de viaje desde los orígenes. Las primeras actualités de los hermanos Lumière, consistían en registrar culturas exóticas en secuencias de un minuto de duración filmadas por operadores que enviaron por el mundo desde los últimos años del siglo diecinueve. Pronto, estos registros del mundo evolucionaron en los travelogues (o travel documentaries) de los años diez y veinte, centrados en la idea de "viaje" e igualmente tratando de sorprender al público occidental con imágenes de un mundo desconocido y por ello fascinante $^{21}$. Como consecuencia, aquellas imágenes se convirtieron en un eficaz instrumento para configurar un imaginario del mundo, no exento de prejuicios y visiones hegemónicas. En cierto sentido, la industria del turismo y la del cine siempre han estado vinculadas narrativamente de manera doble: por un lado, por la acción misma de mirar; por otro lado, por el concepto de viaje, un tropo recurrente tanto en la promoción turística como en los relatos fílmicos.

Llegados a este punto, es interesante observar cómo la simbiosis narrativa de estas dos industrias, la cinematográfica y la turística, se materializa en Andalucía, un film que sin las pretensiones de descubrimiento del lugar, más propia de los reportajes televisivos y documentales, y sin presentar en la pantalla la figura del viajero en el destino turístico, más propia de las agencias publicitarias, parece evocar dichos formatos integrando sus recursos para conformar un relato policíaco de ficción con objetivos muy diferentes. Este proceso de apropiación de recursos narrativos e iconográficos se despliega a lo largo del viaje de los protagonistas. No obstante, no se trata de un viaje a lo desconocido. Andalucía pone en funcionamiento elementos de gran fuerza visual y simbólica que el espectador conoce o puede reconocer porque están disponibles en otros formatos y han sido explotados principalmente por la industria turística. En primer lugar, el recorrido que sigue el diplomático Kuroda acompañado más tarde por Makoto y Yuka en el film no es aleatorio. Su recorrido reproduce el "viaje empaquetado", previamente diseñado y comercializado por las agencias turísticas: París —-Barcelona - Ronda y vuelta a Japón. De este modo, la

21 Musser, Charles (1994): The Emergence of Cinema: The American Screen to 1907. Berkeley: University of California Press; KAR, Law / Bren, Frank (2000): “The Enigma of Benjamin Brodsky". Film Archive Newsletter, noviembre, ${ }^{\circ}$ 14, Hong Kong, pp. 7-11. 
trama policial se ubica cuidadosamente en lugares reconocibles cuya potente iconografía aportan un marco de referencia inequívoco.

El film abre con una sucesión fugaz de imágenes aparentemente aleatorias tomadas desde un coche a lo largo del río Sena, en torno al Arco del Triunfo, frente al Palacio Garnier y finalmente bajo la Torre Eiffel, que ubican al espectador indiscutiblemente en París. Después de un interludio en Andorra, en el cual se encuentran Kuroda, Makoto y Yuka tras aparecer el cuerpo de un inversor japonés aparentemente asesinado, la acción se traslada a Barcelona. La ciudad condal es introducida con un plano general de la estatua de Colón con las ramblas al fondo y el consulado japonés, aunque éste no corresponde con el edificio real en Barcelona. De ahí, Yuka intenta huir y se inicia una persecución filmada en localizaciones en el barrio gótico y el ensanche donde en un par de ocasiones aparece la Sagrada Familia retratada al fondo. A continuación, se realiza un interrogatorio a Yuka en uno de los edificios del puerto de la ciudad, reconvertido en una supuesta oficia de la Interpol. La tercera y cuarta parte del film transcurre en Ronda después de que los protagonistas son atacados en Barcelona por unos siniestros asesinos a sueldo, supuestamente pagados por inversores españoles sin escrúpulos. Los tres protagonistas llegan, supuestamente en AVE, a la ciudad malagueña, que es presentada con imponentes vistas aéreas sobre el desfiladero del Tajo de Ronda y el Puente Nuevo, uno de los símbolos de la ciudad. La siguiente secuencia muestra brevemente el lado más humano de los personajes; Kuroda y Yuka tienen un encuentro cargado de tensión sexual impregnado de iconografía asociada con España: Yuka cae rendida a los brazos de Kuroda después de pasar la noche en el hotel bebiendo vino tinto, mientras Makoto deambula por las casco antiguo donde se retrata la clásica arquitectura rondeña y su plaza de toros. La pasión, un elemento inmaterial que forma parte del imaginario japonés de España, se representa simbólicamente alternando la escena del beso entre Kuroda y Yuka con imágenes de un zapateado flamenco. La intensidad crece por medio de un montaje paralelo entre las bailaoras y la pareja japonesa hasta que Kuroda cae dormido. La secuencia termina con más iconografía tipo, en la que Yuka todavía vestida de color rojo tinto se encuentra con Makoto en la plaza de toros.
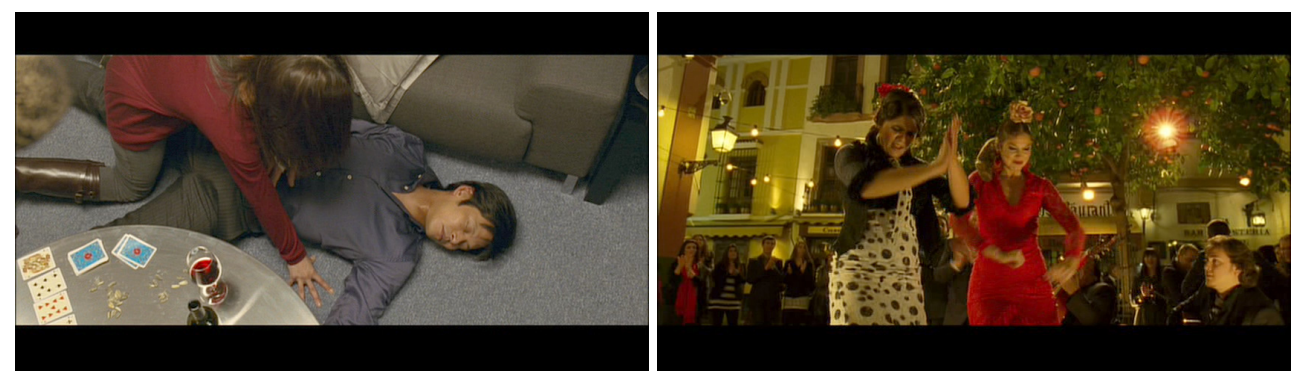

Fig. 1. Fotogramas de Andalucía (Andarushia, Nishitani Hiroshi, 2011).

A lo largo de dichas secuencias, es interesante observar cómo, en gran medida, el atractivo de la trama de suspense reside en el hecho de que se desarrolla en lugares exóticos, pero a la vez identificables para el público japonés. Se trata de entornos si bien no familiares, sí reconocibles porque Andalucía recurre a elementos explotados por las 
agencias japonesas dedicadas a la promoción de los viajes a España. Para ilustrar esta cuestión, hemos comparado el film con una veintena de folletos turísticos distribuidos en las agencias japonesas, en los cuales se publicita España como destino turístico. A primera vista, resulta significativo el papel central que ocupa el concepto de "viaje", su conversión de mero desplazamiento geográfico a experiencia cultural que en última instancia deviene un objeto de consumo. Es necesario matizar que no nos referimos aquí al inevitable viaje de Japón a España, que apenas guarda un papel destacado en los folletos, sino al "viaje en España". El principal reclamo no es tanto convivir con la gente local o conocer en profundidad una localidad sino moverse continuamente para visitar el mayor número de ciudades en el menor tiempo posible.

De este modo, existe un interesante paralelismo entre Andalucía y los folletos turísticos, en la medida en que en ambos casos, el tema central es el viaje en sí mismo. El viaje no sólo se convierte en un recurso narrativo turístico y cinematográfico sino que además se construye en ambos casos sobre un recorrido considerablemente similar. Comenzando por Barcelona, la elección de la ciudad condal como tercera localización del film en orden de aparición, después de París y Andorra, y en particular el retrato de la Sagrada Familia, es explicable por su eficaz función referencial: la imagen de la catedral de Gaudí ocupa continuamente un lugar destacado en la promoción japonesa de viajes a España. [fig. 2] Además, la Sagrada Familia es uno de los principales recursos visuales para la promoción de viajes por Europa. En los folletos orientados a los viajes transnacionales, el continente europeo queda sintetizado en un número muy reducido de referentes iconográficos, entre los que se encuentra la Sagrada Familia junto al Domo de Florencia y la Gruta Azul (Grotta Azzurra) de Italia, el Mont-Saint-Michel y la Torre Eiffel en Francia, y el castillo de Neuschwanstein de Alemania. La inclusión del monumento barcelonés en esta selecta batería de imágenes fácilmente reconocibles para el turista japonés es un ejemplo de su tremenda fuerza icónica.
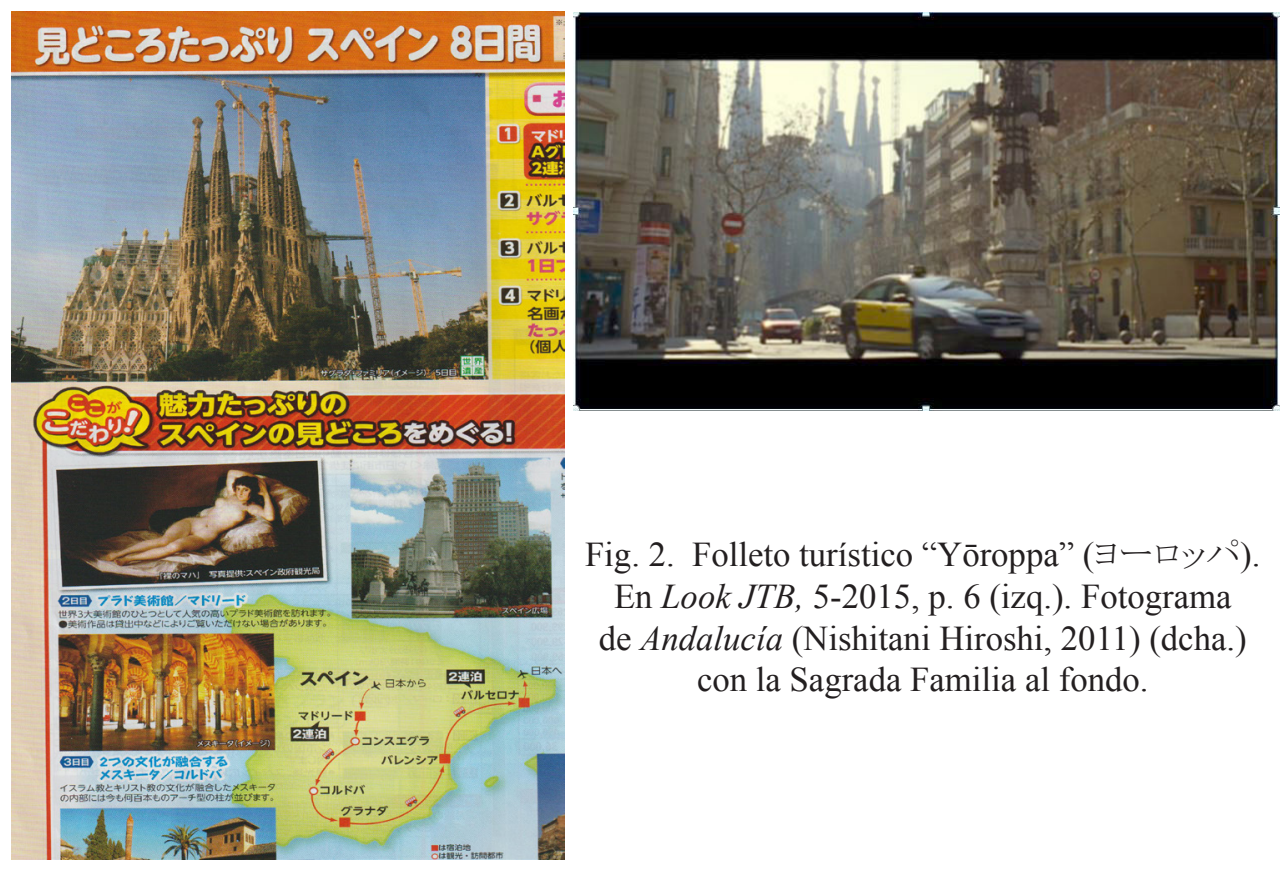

Fig. 2. Folleto turístico "Yōroppa" (ヨーロッパ). En Look JTB, 5-2015, p. 6 (izq.). Fotograma de Andalucía (Nishitani Hiroshi, 2011) (dcha.) con la Sagrada Familia al fondo. 
En el diseño japonés de los viajes por España, además de la Sagrada Familia, los folletos turísticos colocan en otro lugar destacado un monumento aparentemente ineludible para la promoción del patrimonio cultural español, la Alhambra en Granada. No obstante, resulta menos obvia la elección de otros destinos que, independientemente de su atractivo e interés turístico, no serían necesariamente los iconos más emblemáticos del país para un local: el Puente Nuevo de Ronda, las casas blancas de Mijas, también en la provincia de Málaga, y los molinos de Consuegra en Toledo.

De este análisis, se extrae que si bien Andalucía no reproduce el paso por todas las principales localidades promocionadas por las agencias de turismo - los protagonistas no pasan por Granada ni Toledo y Andorra no es un reclamo importante en estos folletos-, la elección de otras localizaciones como la Sagrada Familia, la Torre Eiffel, y sobre todo Ronda, donde se desarrolla más de un cuarto de la película, son referentes que tienen más que ver con las sinergias, influencias o mímesis procedentes de las actividades de promoción turística que con una justificación narrativa en el film. De esta manera, la construcción del viaje por España a través de estos folletos resulta un instrumento útil para explorar cómo se forma al imaginario del país en un entorno extra-cinematográfico que acaba por tener un impacto sobre lo que se muestra en la pantalla. A lo largo de este proceso, tanto los folletos como el film acaban por recurrir a una iconografía sencilla y repetitiva, que conecta con lo que el turista/espectador potencialmente ya conoce. [fig. 3]
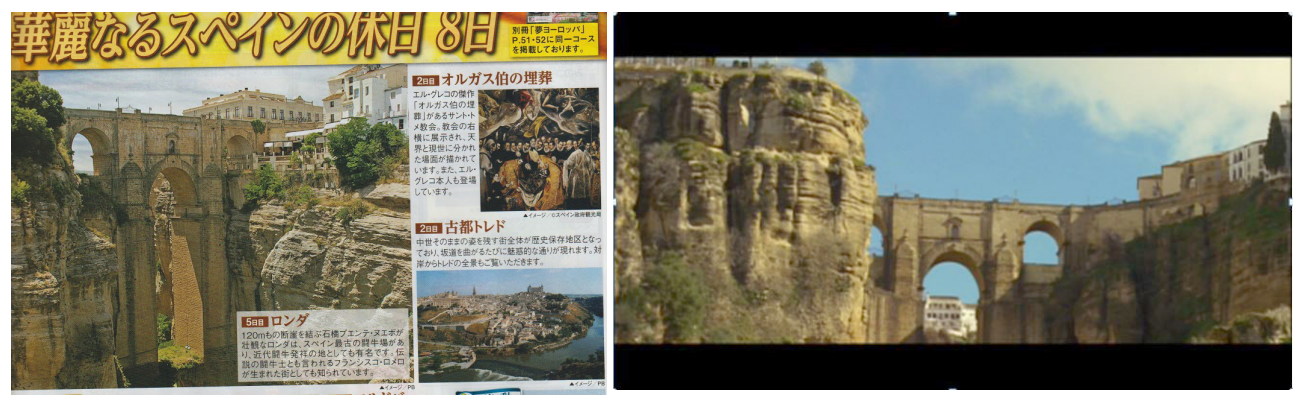

Fig. 3. Imágenes de Ronda (Málaga) en el folleto turístico. Supein, Furansu, Porutogaru, Igirisu (スペイン・フランス・ポルトガル・イギリス), 6-2015, p. 15 (izq.).

Fotograma de Andalucía (Nishitani Hiroshi, 2011) (dcha.) del puente de Ronda.

\section{Transferencia iconográfica: del folleto turístico al cine}

Dicho esto, la batería de imágenes compartidas provenientes de los folletos turísticos no se reduce al reclamo monumental y paisajístico. Un considerable número de secuencias de Andalucía contienen un heterogéneo grupo de elementos de la cultura española que las agencias japonesas proponen descubrir: la gastronomía, habitualmente reducida a las tapas, el vino tinto, el gazpacho y la paella. Los dos primeros aparecen en el film con la función de marca referencial, o dicho de otro modo, sirven para recordar al espectador que los protagonistas se mueven en un 
contexto cultural distante. Sin embargo, el exotismo en las escenas no surge del choque cultural sino al contrario, de la familiaridad con la que los protagonistas se desenvuelven en este entorno. Kuroda se reúne en una taberna de Barcelona con Adachi Kanae (Toda Erika) una diplomática que trabaja para el consulado japonés que no oculta su atracción hacia el detective mientras comen tapas y hablan sobre las sospechosas transferencias de capital del Banco Victor. Aunque Kuroda rechaza las insinuaciones de Kanae, de nuevo, se vuelve a producir un llamativo fenómeno de asociación en el cual, cuando los personajes son retratados consumiendo gastronomía española, pasan a encarnar una pasión atípica y exagerada, pero inequívocamente asociada a los mitos de lo hispano. Otros ejemplos ilustran esta suerte de exotismo postmoderno, que no se produce por un fenómeno de alienación o exaltación de la diferencia sino por una nueva forma de familiarización con la otredad. Aunque la mayor parte de las conversaciones transcurren en japonés, todos los personajes japoneses son retratados comunicándose ocasionalmente en castellano e incluso en inglés y francés. El resultado son atractivas figuras transnacionales que de alguna manera vienen a encarnar las ensoñaciones del turista que busca el encuentro con otra cultura. [fig. 4]
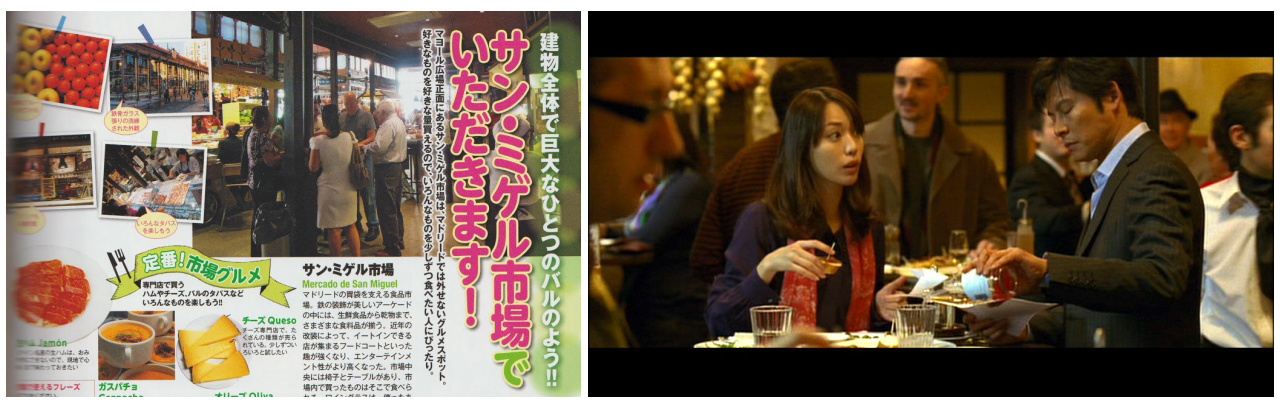

Fig. 4. Folleto turístico. Supein, (スペイン). Tokio: K\&B Publishers, 15/06/2015, p. 66 (izq.). Fotograma de Andalucía (Nishitani Hiroshi, 2011) (dcha.)

Asimismo, Andalucía despliega ciertas estrategias visuales no originales, desarrolladas en los folletos turísticos como la combinación de viejos elementos del imaginario español con otros modernos. De este modo, el paseo de Makoto por las calles de Ronda le lleva a toparse con un espectáculo flamenco y termina en la plaza de toros de la ciudad, donde aparentemente se están formando futuros toreros. Sin embargo, en la siguiente escena se retrata una policía con equipos altamente sofisticados para llevar a cabo la operación y capturar a los inversores corruptos. Asimismo, en la secuencia anterior, los protagonistas viajan de Barcelona a Ronda en el tren de alta velocidad. La filmación de los personajes en tren resulta significativa pues el AVE suele incluirse en los folletos turísticos para promocionar la idea de viaje rápido y cómodo por España. En consecuencia, este ejemplo indica que no todos los referentes visuales del film proceden de iconografías asentadas del pasado y señala la existencia de un fenómeno de transferencia de imágenes a la gran pantalla más ligado a la promoción turística japonesa que a la herencia cultural española. [fig. 5.] 
La iconografía tipo utilizada en Andalucía permite contextualizar la trama representando un entorno no necesariamente riguroso con su realidad social, pero fiel a la imagen prefijada con la que el espectador japonés puede estar más familiarizado. Como resultado, las secuencias descritas remiten a ideas previamente conocidas por el espectador, y el turista, ofreciendo la falsa percepción de que ya conoce el lugar. No obstante, a diferencia de lo que habitualmente se piensa, el imaginario de lo español no es universal. La imagen de España no se construye igual en cualquier otro país y de hecho, la iconografía japonesa de España presenta elementos propios que no coinciden necesariamente con la elaborada en otros países. Esta construcción está sujeta a los intereses, gustos, el grado de exotismo o cercanía de cada lugar y tiene poco que ver con el destino en cuestión. Por ejemplo, mientras el turismo europeo se mueve interesado por el clima y se concentra en las zonas de la costa mediterránea, el público japonés se siente más atraído por el turismo cultural que por el sol y la playa ${ }^{22}$. Esto explica en los folletos japoneses, la ausencia de playas, complejos hoteleros en la costa o referencias a Ibiza, Benidorm o Islas Canarias que domina la promoción turística de España en Europa. Sin embargo, estos atractivos son sustituidos por un gran número de referencias a los museos y la pintura, representada en los folletos en tres cuadros, la Maja Desnuda de Goya, El Entierro del Conde de Orgaz de El Greco y Las Meninas de Velázquez.

De esta forma, a diferencia de otras películas europeas sobre España o películas españolas orientadas a la promoción del propio país, Andalucía no contiene panorámicas de playas, ni referencias al sol. El imaginario japonés de España es por tanto sui generis, no corresponde exactamente al existente en otros países europeos, ni tampoco con el que los españoles tienen de sí mismos. Esto se debe a que la representación visual y alegórica de un país es un proceso complejo en el que intervienen factores sujetos a intereses de distinto tipo y con frecuencia ajenos al lugar de origen. Por ello, aunque Afinoguénova describe el turismo como una actividad centralizada, administrada por el Estado, que crea un discurso oficial y puede ser un importante promotor de la identidad nacional ${ }^{23}$, esta postura ignora la existencia de otros agentes que intervienen en la formación de este imaginario como los autores, los medios de comunicación y de expresión extranjeros. De entre ellos, este trabajo trata de resaltar el papel de cineastas, productoras audiovisuales y agencias turísticas japonesas, por su capacidad para generar iconografías que escapan a la construcción turística institucional del país y demuestran que el estado no es el único actor en este proceso. De esta forma, el caso de Andalucía ilustra la creación de un imaginario nacional desde el exterior, basado en un complejo fenómeno de transferencia intertextual de imágenes entre la industria turística y la cinematográfica. Esta representación se elabora en función de los intereses de ambos sectores, cuya principal motivación no es ofrecer una versión actualizada de los situación social de España ni reflejar su diversidad cultural y geográfica, sino reproducir una percepción japonesa sobre España preexistente que es actualizada utilizando elementos que más puedan atraer al público japonés sin traicionar demasiado sus expectativas.

\footnotetext{
22 Mestre, Rosanna (2007): “Anime español para otaku japoneses”. En: Del Rey Reguillo, Antonia (ed.), Cine, imaginario y turismo..., op. cit., p.226.

23 AfinoguénOva, Eugenia (2007): "Discurso del Turismo...”, op.cit., pp. 35-53.
} 

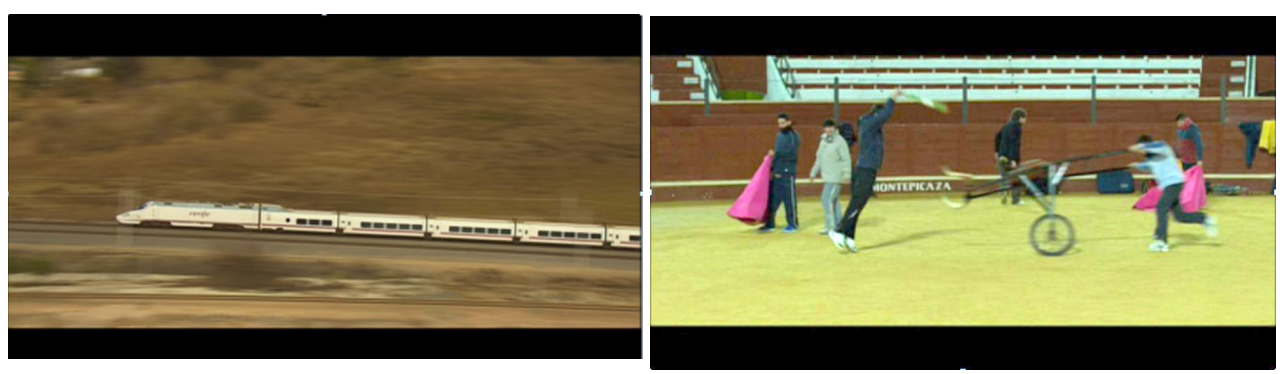

Fig. 5. Fotogramas de Andalucía (Nishitani Hiroshi, 2011)

De este modo, resulta interesante observar que el viaje propuesto en Andalucía de Barcelona a Ronda sigue patrones semejantes al presentado en los folletos turísticos en el sentido que eluden un retrato de la división geográfica y política del país. Como señala Stanishevski, los "límites geográficos no son determinantes para la definición de un destino turístico como tal" 24 . Por un lado, las rutas turísticas promocionadas en los folletos no prestan demasiada atención a los límites político-administrativos sino a otras categorías, ofreciendo una lectura global, aglutinadora, tremendamente ambiciosa e igualmente vaga con eslóganes tipo "conoce toda España en ocho días", sin aportar ningún dato sobre la lengua, historia o geografía del lugar. Por otro lado, Andalucía recurre a este modelo de viaje que presta más atención a la visión homogeneizadora que a las diferencias regionales. Como consecuencia, aunque aparecen personajes secundarios hablando en lengua catalana, estos son sólo retratados en las secuencias filmadas en Andorra; en Barcelona todos hablan castellano. Y el castellano se presenta uniforme a lo largo de la película, ignorando las variaciones catalanas en Barcelona y las andaluzas en Ronda. Asimismo, en la taberna de Barcelona en la que Kuroda charla con la empleada del consulado japonés, se sirve sangría y tapas de jamón y queso, sin que en el film muestre ninguna variedad gastronómica, no hay referencias al cava, los calçots o la butifarra de Cataluña como tampoco se retratan el gazpacho andaluz ni otros platos locales como la sopa de castañas o la perdiz del tajo en las escenas de Ronda. Por tanto, lo que el espectador encuentra en el film es una serie de elementos contextuales que aluden al imaginario japonés de la cultura española conocido de antemano. No se trata de una visión compleja que intente aportar nuevos matices de la pluralidad española sino una representación narrativamente más simple, pero eficaz, que busca indicar que lo que se está viendo sucede inequívocamente en España, tratando de evitar demasiados datos que el público japonés pueda potencialmente no conocer. Paradójicamente se trata de una estrategia similar a las promociones turísticas de manera que en ambos casos, se recurre a convenciones visuales, mapas mentales e ideas prefijadas que encajen con los horizontes de expectativas de espectadores y turistas. Los elementos desplegados en Andalucía se suman a este consenso sobre el conocimiento colectivo y estereotipado de la cultura española. 


\section{Turismo de películas y películas de turismo}

Parte de la literatura sobre las relaciones entre cine y turismo se ha centrado en la instrumentalización del cine por la industria turística, es decir, el estudio de los casos en los que un destino turístico se ha beneficiado por el éxito de una película ${ }^{25}$. En relación al caso particular japonés, algunos autores han acuñado el concepto de "turismo de contenidos" (contents tourism) para referirse a aquel turismo inducido por los medios ${ }^{26}$. Un ejemplo es el aprovechamiento de la serie televisiva La vida de Ryoma (Ryōma-den, 2010) o la película El último samurai (The Last Samurai, Edward Zwick, 2003) para fomentar el turismo local ${ }^{27}$. Estas investigaciones han tratado de esclarecer cómo se genera un "turismo de patrimonio" (heritage tourism) basado en la calidad de sus contenidos, las narraciones y personajes asociados a él. Existen ejemplos, como el de Braveheart (Mel Gibson, 1995) que hizo doblar las visitas al Wallace Monument en Stirling el año de su estreno ${ }^{28}$. En relación a esto, algunos autores han hablado del "turismo de películas" (film tourism) que en ocasiones ha producido un aumento de visitantes a un lugar ${ }^{29}$.

No obstante, aplicar esta perspectiva de análisis al caso de Andalucía es problemático pues es difícil saber si este film genera un tipo de "turismo de películas". A diferencia de Braveheart o El último samurai que toman historias locales y las empaqueta para una audiencia global, Andalucía es un thriller-drama de ficción que no retrata historias ni leyendas de Barcelona o Ronda, sino que proyecta otros estereotipos vinculados genéricamente a lo español, reconocibles en Japón, por tanto es difícil saber si existe turismo japonés que llega a motivado por el film y en qué medida éste condiciona la decisión de viajar a estas dos ciudades. Esta cuestión es especialmente difícil de esclarecer en el caso de Barcelona, por el volumen de visitantes japoneses que acuden a la ciudad por distintos motivos. En el caso de Ronda, la principal motivación de los visitantes japoneses es la turística y según la Oficina Municipal de Turismo, las visitas procedentes de Japón ha aumentado desde el estreno del film en 2011. No obstante, tampoco es fácil determinar el impacto que ha tenido Andalucía en estos datos, pues el turismo extranjero en la ciudad ya había aumentado el año anterior en un $63 \%{ }^{30}$.

25 Busby, Graham / Klug, Julia (2001): "Movie-induced tourism: The Challenge of measurement and other issues". En: Journal of Vacation Marketing, 3(4), pp. 316-328; SEATon, Philip (2014): "Taiga dramas and tourism: historical contents as sustainable tourist resources", op.cit., pp. 82-103.

26 Nishikawa, Katsuyuki et al. (eds.) (2015): The Theory and Practice of Contents Touris... op.cit.

27 Seaton evalúa la posibilidad de que El último samurái hiciera aumentar las visitas a la prefectura de Hyogo y el Templo Engyōji de la ciudad de Himeji, pero no obtiene datos concluyentes, pues el film es un agente más que se suma a las estrategias nacionales y locales de promoción. SEAton, Philip (2014): "Contents Tourism and the (Hi)story of the "Last Samurai". En: TTRA International Conference: Tourism and the New Global Economy, pp. 1008-1027.

28 Edensor, Tim (2005): "Mediating William Wallace: Adio-visual technologies in tourism”. En: CROuCH, R. Jackson / Thomspon, Felix. (eds.), The Media \& the Tourist Imagination: Converging cultures. London: Roughtlede, pp.105-118.

29 Rosado Cobián, Carlos / Fernández Querol, Piluca (2006): Cine y Turismo. Una nueva estrategia de promoción. Sevilla: Ocho y Medio. Los nexos teóricos entre el "turismo de películas" y el "turismo de patrimonio" han sido desarrollados en Frost, Warick (2006) "Braveheart-ed Ned Nelly: historic films, heritage tourism and destination image". En: Tourism Management, 2006, 27: 247-254.

30 Ha habido un aumento en los últimos años del turismo asiático en Ronda, pero la noticia señala que se debe principalmente a los turistas de origen chino. Según los datos del Instituto Nacional de Estadística (INE) y la Oficina Municipal de Turismo de Ronda, el número de visitantes de otros países a Ronda ha crecido un 63,03\% desde 2010 hasta 2014. En 2010, pasaron por la Oficina 96.325 extranjeros, mientras que el mismo dato en 2014 
Llegados a este punto, debemos precisar que analizar si Andalucía ha tenido un efecto visible en la industria turística excede los límites de esta investigación. La intención de este texto, sin embargo, no es determinar si el film ha generado un tipo de "turismo de películas" sino si el film constituye un tipo de "película de turismo" de sentido contrario, en la que se pone de relieve la instrumentalización de relatos e iconos utilizados por el turismo con fines cinematográficos. ¿Qué relación guarda esta "película de turismo" con otros films ambientados en España? Los autores del grupo de investigación CITUR han realizado con anterioridad una útil clasificación de tres tipos de películas según la forma en que se construye la imagen de España: "films icono", "films pastiche" y "films de poster turístico"31.

Primero, según estos autores, la "película icono" (icon film) actuaría como ejemplo de producto cultural de un país, en la que se valora el conocimiento que el director tiene del lugar. Sus ciudadanos perciben el film como una realidad cercana y se reconocen en él. Valdría como ejemplo japonés Cuentos de Tokio (Tokyo monogatari, 1953) de Ozu Yasujirō y de ejemplo español Bienvenido Mister Marshall (1953) de Luis García Berlanga o Volver (2006) de Pedro Almodóvar, donde estereotipos que el mundo entiende genuinos del país están omnipresentes, pero en una forma inusual y renovada. Segundo, los autores identifican un tipo de "películas pastiche" (pastiche films) que falsean la realidad referencial reforzando estereotipos de forma distorsionada. Todo film es de alguna manera pastiche, pero estos films no necesariamente representan una realidad, hacen referencias a ella y se caracterizan por la falta de rigor. Un ejemplo sería Misión Imposible 2 (Mission: Impossible II, 2000) de John Woo ambientada en una Sevilla creada digitalmente, que usa clichés conocidos de las bailadoras de flamenco combinado con unas tomas de mujeres vestidas con trajes tradicionales de las Fallas de Valencia y los Castillos de Alicante, y otras de hombres vestidos con camisa blanca y el pañuelo rojo de San Fermín en Pamplona.

Andalucía difícilmente se puede incluir en ninguna de estas dos categorías. No presenta el conocimiento profundo del contexto socio-cultural que se le presupone a la "película icono". Aunque proyecta una visión esquemática y simplista de España, no falsea descaradamente la representación del lugar: en las escenas en Andorra se introduce al personaje de Makoto practicando esquí, en Barcelona los protagonistas encuentran un castell y en Ronda se filman escenas por las calles del casco antiguo. Sin embargo, Andalucía encaja bien con la tercera categoría definida como "películas de poster turístico" (tourist poster films) en las que la trama recorre ciertos monumentos y paisajes del lugar. Por tanto, tienen un contenido potencialmente publicitario de la zona, ciudad o el país donde se localiza la historia. Ejemplos de este grupo serían Vacaciones en Roma (Roman Holiday, William Wyler, 1953) o El cielo protector (The Sheltering Sky, Bernardo Bertolucci, 1990) en los que la historia romántica, policía, de aventuras, o combinada - gira en torno a un viaje en el marco de un destino turístico. Esta categoría resulta interesante porque permite estudiar el film en términos de experiencia cultural similar a la del viajero. Este hecho es especialmente significativo en Andalucía, donde la simbiosis con el turista es tal que los protagonistas son retratados recreando las mismas actividades: se alojan en distintos

subió hasta los 157.037. Los turistas nacionales no crecieron tanto como los extranjeros: de los 232.489 turistas que acudieron a la Oficina en 2014, tan solo 75.452 fueron de origen nacional. Vid noticia online:

http://www.diariosur.es/turismo/201503/16/ronda-fija-mirada-flujo-20150316002209-v.html [Consulta: 10/11/2016]

31 Mestre, Rosanna / Del Rey Reguillo / Antonia / Stanishevski, Konstantin (2008): "The Image of Spain as Tourist Destination Built Through Fictional Cinema", op.cit. 
hoteles y se pasean por el casco viejo de las ciudades a través de los mercados de abastos o las boutiques de moda y donde se encuentran con los mismos atractivos culturales que se promocionan turísticamente. Por ejemplo, gracias a la información que le proporciona el periodista Shogo Saeki (Fukuyama Masaharu), Kuroda comienza a descubrir que la muerte del inversor japonés puede estar vinculada a un caso de blanqueo de dinero del Banco Victor. El encuentro entre Kuroda y Shogo tiene lugar en la Plaza de España de Barcelona, donde una colla castellera levanta una torre humana frente al Estadio Olímpico de Montjuïc. Shogo es retratado de forma ambigua a caballo entre el rol de periodista y la figura del turista que trata de inmortalizar su viaje con la cámara de fotos. [fig. 6]
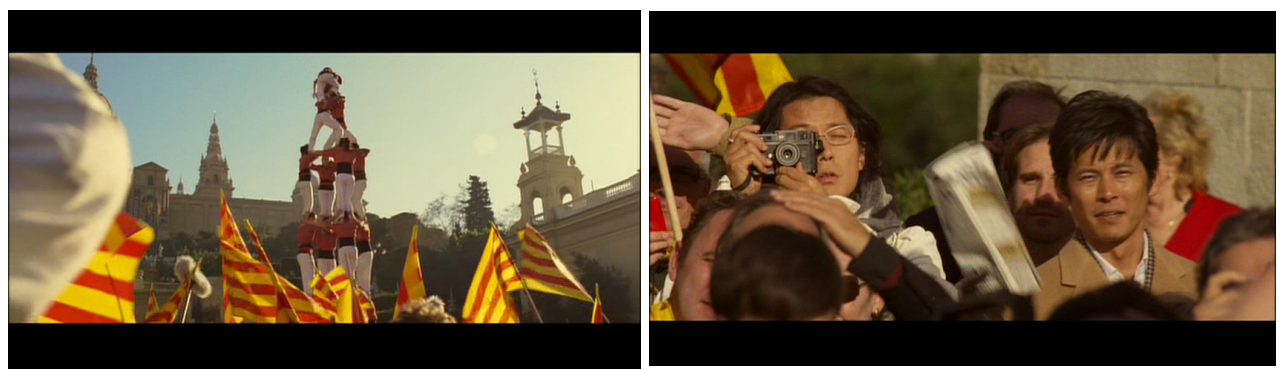

Fig. 6. Fotogramas de Andalucía (Hiroshi Nishitani, 2011). Castell frente a Montjuïc (izq.), Makoto y Shogo Saeki contemplando el espectáculo (dcha.)

\section{Relaciones sexualizadas de Japón con Occidente}

Al igual que Kuroda, el personaje de Shogo encarna otra sugerente figura transnacional cuyo atractivo se basa en la interacción con un entorno exótico con el que aparentemente está familiarizado pese a ser japonés. De la torre humana baja una entusiasmada joven española (San Yélamos) que saluda efusivamente cada vez que entra en escena, con la que Shogo mantiene una relación amorosa y se comunica en castellano. En este caso, no es que Shogo reproduzca la experiencia del visitante japonés en España, sino que más bien encarna las fantasías del turista ligadas a este contacto entre la cultura de origen y la de destino. [fig. 7]

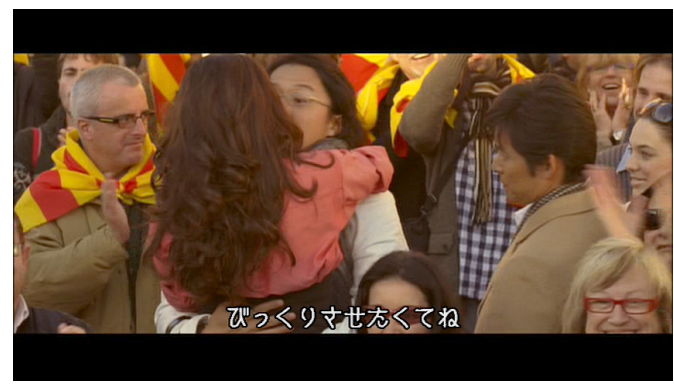

Fig. 7. Fotograma de Andalucía (Nishitani Hiroshi, 2011)

No obstante, esta representación del contacto de Japón con el extranjero en términos de género no es nueva. En la iconografía japonesa cuenta con abundantes ejem- 
plos. Estas representaciones a menudo evocan simbólicamente la relación de poder de Japón con otros países, que en la historia cultural Igarashi ha estudiado como una relación "sexualizada" 32 . Las relaciones de Japón con Occidente han recurrido frecuentemente al mito de "Madame Butterfly" de John Luther Long que Giacomo Puccini convirtió en opera, donde Estados Unidos es representado en términos masculinos, asociados al concepto de poder, dominación y sujeto activo; mientras Japón se encarna en papeles femeninos, mezclados con atributos de sumisión, obediencia, fidelidad y el objeto de deseo. Este esquema de representación se ha repetido en decenas de versiones y adaptaciones cinematográficas realizadas en Estados Unidos, Europa y Japón, desde la primita versión fílmica de Sidney Olcott de 1915 o el film dirigido por Marion Grain en 1936, protagonizado por Gary Grant, pasando por la coproducción ítalo-japonesa de 1954 dirigida por Carmine Gallone, hasta la versión de Frédéric Miterrand filmada en Túnez en 1995. Desde la posguerra, se recuperaron estas convenciones masculinidad occidental-feminidad oriental que en realidad proyectaban a través de las relaciones de género ciertos traumas y complejos de inferioridad la relación con el país norteamericano ${ }^{33}$.

No obstante, Andalucía presenta una versión hasta cierto punto actualizada en la relación de Japón con Occidente. Por un lado, tenemos el romance de Shogo con la efusiva chica española de la que nada se sabe aparte de encarnar la pasión estereotipada española que recupera el mito de Carmen. Sin embargo, se trata de una imagen renovada y modificada del personaje creado por Prosper Mérimée e inmortalizada en la ópera de Georges Bizet, donde la gitana sevillana es reconvertida en una joven catalana enamorada de un extranjero que ya no es un soldado francés sino un periodista japonés. La relación entre la mujer catalana y Shogo es interesante no sólo porque plantea la imagen orientalista de España, que atraía a los primeros viajeros románticos, sino porque invierte el rol de género tradicionalmente atribuido a la relación de Japón con Occidente. En esta ocasión, el personaje japonés representa la masculinidad, la autoridad y el poder; mientras su amante española, encarna la feminidad, lo salvaje y lo pasional.

Estos romances transnacionales evocan simbólicamente relaciones de poder, o dicho de otro modo, una suerte de jerarquización imaginaria de naciones que necesitarían ser herramientas y métodos en el ámbito de la psicología social para una evaluación completa de esta cuestión. Centrándonos en los mecanismos de representación en Andalucía, los personajes presentan a lo largo del film una relación desigual con los países occidentales. El comportamiento y las motivaciones de los personajes japoneses difieren significativamente dependiendo de si interactúan con españoles o con norteamericanos. En cada caso, se despliega un aparato narrativo y alegórico diferente. Los vínculos con lo español tienen que ver con la pasión; cuando los protagonistas actúan impulsivamente siempre entran en escena elementos como el vino, las tapas o el flamenco. La relación con los Estados Unidos es por el contrario, del todo racional y estratégica: el mandatario nipón Murakami Seijuro (Natsuyagi Isao)

32 Igarashi, Yoshikuni (2000): Bodies of Memory. Narratives of War in postwar Japanese Culture, 1945-1970. Princeton: Pricenton University Press.

33 La encarnación de Estados Unidos en personajes masculinos dominantes y poderosos y Japón en personajes femeninos sumisos a partir del cine juvenil de posguerra ha sido abordada Centeno Martín, Marcos (2015): "Transcultural Corporeity in Taiyozoku Youth Cinema. Some Notes on the Contradictions of Japaneseness in the Economic Miracle". En: Becker, Andreas / AdAchi-RABE, Kayo (eds.): Körperinszenierungen im japanischen Film/Presentation of Bodies in Japanese Films. Darmstadt: Büchner-Verlag, pp.143-160. 
necesita el apoyo de su homólogo norteamericano para conseguir aprobar en una cumbre internacional su proyecto de control bancario y lucha contra el fraude fiscal, frente a otros países, incluidos los europeos, que son reacios.

El planteamiento narrativo contiene una importante connotación ideológica sobre la percepción de Japón y sus alianzas en el mundo. Estados Unidos no sólo es presentado en el film como el principal apoyo de Japón, sino que además es quien mejor entiende sus problemas. El señor Murakami confiesa que la única opción de sacar su proyecto adelante pasa por que su colega americano persuada a los europeos, de manera que el papel internacional de Japón queda siempre hipotecado a su relación con Estados Unidos. Decíamos que el film señala relaciones simbólicas desiguales, porque mientras Japón depende de la ayuda diplomática de Estados Unidos, España depende de la ayuda de Japón para hacer frente al crimen y la corrupción bancaria. Ambos países son retratados en niveles diferentes respecto a Japón. Este fenómeno es significativo en el tratamiento de personajes. El estadounidense encarna una figura patriarcal, comprensiva y magnánima, pero ante todo, poderosa, pues hasta se permite bloquear una calle del centro de París al inicio de la película, para almorzar sardinas a la piedra en un pequeño bistrot. Se establece una relación homoerótica de sumisión hacia Estados Unidos donde Japón pierde aquella "masculinidad" ostentada en su relación con España. Por el contrario, los personajes españoles, a excepción del banquero corrupto, se ven alejadas de las élites mundiales, de hecho en la cumbre de países europeos no aparecen representantes españoles. Sus figuras están ligadas a la calle y a lo popular: la joven amante de Shogo surge por primera vez de las masas y la tradición, la torre de los castellers, y el agente de policía español que acompaña a Kuroda y Makoto viste de forma llamativamente informal, con gorra, chupa de cuero, se insinúa a Yuka cada vez que tiene ocasión y en su camiseta se puede leer "soy un vividor". [fig. 8]
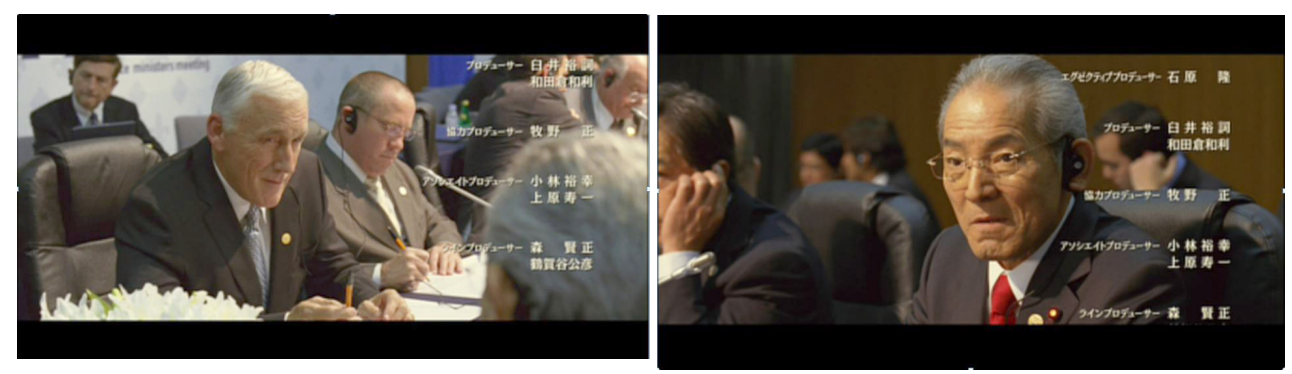

Fig. 8. Fotogramas de Andalucía (Nishitani Hiroshi, 2011)

\section{Corrupción: ¿nuevos estereotipos?}

Las secuencias descritas señalan el uso en Andalucía de estereotipos asentados así como percepciones, mentalidades e ideologías preexistentes. Pero además, el film incorpora referencias a hechos de actualidad que no deben pasar por alto, principalmente la corrupción, el blanqueo de dinero y las cuentas en Andorra. Curiosamente, el film parece anticipar los casos de malversación y cohecho del expresidente de la Generalitat Jordi Pujol y miembros de su familia, tres años antes que se diera a cono- 
cer en 2014 la existencia de dinero no declarado en bancos en Andorra. Sin embargo, Andalucía bien podría haberse hecho eco las corruptelas políticas que llevaban salpicando la percepción extranjera del país varios años antes del estreno de Andalucía, como el caso Gúrtel que estalla en 2009 o el caos Nóos a partir de 2010. Todavía es pronto para decir si estos aspectos negativos son pasajeros o se consolidarán como estereotipos del imaginario español. [fig. 9]

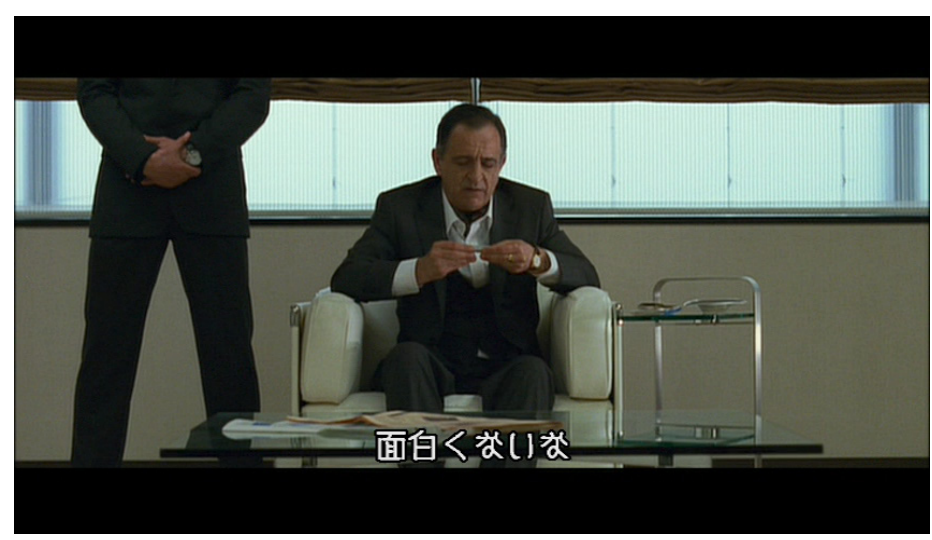

Fig. 9. Fotograma de Andalucía (Nishitani Hiroshi, 2011)

¿Cómo es posible que estos acontecimientos tan recientes hayan podido filtrarse con tanta rapidez en el imaginario de España, cuando otros elementos arquetípicos llevan construyéndose durante siglos? Algunas de las claves para entender este fenómeno cinematográfico se pueden encontrar en las teorías comunicativas de los gate keepers, que señalan que en los países democráticos un evento tiene mucha más posibilidades de convertirse en una noticia cuando se trata de bad news ${ }^{34}$. Estas noticias son obviamente perjudiciales para la imagen de un país en el exterior, pero son good news para los gestores de los medios que permiten, o más bien, promueven, que estas noticias fluyan con mayor rapidez ${ }^{35}$. De este modo, la asociación de España con la corrupción financiera y el blanqueo de capitales que se presenta en Andalucía parece haber dado al traste con el intento de promover mediante el cine una renovada imagen positiva del país en Japón, que había comenzado con la iniciativa institucional de Gisaku, estrenada en 2015.

\section{Conclusión}

Si bien el cine de ficción puede ser un poderoso agente cultural que modela la imagen internacional de un país y coloniza el imaginario de los espectadores, este trabajo propone el estudio de un fenómeno inverso: interrogar las imágenes preexistentes de un país, en este caso las que promueven el turismo en España, e identificar

Wolf, Mauro (1987): La investigación de la comunicación de masas. Barcelona: Paidós.

StAnishevski, Konstantin (2007): "La comunicación de los destinos turísticos”, op.cit., pp.245-267. 
mecanismos de reapropiación cinematográfica. Como consecuencia, la metodología empleada para el estudio de Andalucía dice poco sobre la influencia del cine en el turismo, pero se pone en práctica para revelar claves en sentido inverso, el impacto del turismo en el cine. La construcción del imaginario de España en el film, al igual que en los folletos turísticos, es eminentemente esencialista y tipificada, articulada en ambos casos con una intención muy concreta, seducir al público japonés. De este modo, las agencias turísticas no buscan un retrato matizado de la sociedad y cultura de destino, sólo una versión sesgada, interesada y mediatizada. Andalucía plantea un recorrido por España similar al viaje publicitado en los folletos turísticos, dominado por una codificación basada en ensoñaciones y mitos que son reinterpretados para encajar con las expectativas del espectador y el turista nipón.

El análisis del film permite observar cómo los elementos de la supuesta cultura tradicional local - flamenco, toros, gastronomía - y conceptos asociados a ella pasión, exotismo - transitan de la narración turística a la narración cinematográfica, incluyendo la transformación de destinos turísticos en localizaciones fílmicas. Los elementos de iconografía española son utilizados para proyectar paradójicamente una otredad conocida con el fin de generar un fenómeno simultáneo de reconocimiento y asombro en el espectador japonés. Lejos de profundizar en la diversidad social, heterogeneidad cultural, en los problemas socio-económicos o en las contradicciones identitarias del país, se presenta un escenario bucólico compuesto por elementos cuidadosamente seleccionados que refuerzan en gran medida una imagen descontextualizada, aunque no completamente desligada de la actualidad del país, como indican las referencias a la corrupción financiera y el blanqueo de dinero. Este hecho revela la existencia de mecanismos de codificación del país, que en parte recurren a viejos estereotipos para recrear irónicamente un exotismo conocido, pero en parte renueva el imaginario de España y actualiza la experiencia del viajero en la pantalla con referencias más actuales y protagonistas transnacionales cuyas relaciones con el entorno no dejan de reflejar metafóricamente la relación de Japón con el mundo. 